Article

\title{
Suicide Risks among Adolescents and Young Adults in Rural China
}

\author{
Sibo Zhao ${ }^{1,2}$ and Jie Zhang ${ }^{1,3, *}$
}

1 School of Social Development, Central University of Finance and Economics, Beijing 100081, China

2 Department of Sociology, State University of New York at Buffalo, Buffalo 14260, USA;

E-Mail: sibozhao@buffalo.edu

3 Department of Sociology, State University of New York College at Buffalo, Buffalo 14222, USA

* Author to whom correspondence should be addressed; E-Mail: zhangj@buffalostate.edu;

Tel.: +1-716-878-6425; Fax: +1-716-878-4009.

Academic Editors: Danuta Wasserman, Vladimir Carli and Gergo Hadlaczky

Received: 10 September 2014 / Accepted: 16 December 2014 / Published: 23 December 2014

\begin{abstract}
Background: In China, suicide is one of the major causes of death among adolescents and young adults aged 15 to 34 years. Aim: The current study examines how risk factors vary by age groups in rural China, referring to those aged 15 to 24 years and those aged 25 to 34 years. Method: A case-control psychological autopsy (PA) study is conducted in sixteen counties from three Chinese provinces, including 392 suicide cases and 416 community living controls in the sample. Results: In China, young adults aged 25 to 34 years have a higher risk for suicide than adolescents aged 15 to 24 years, and it holds true even controlling for relevant social factors. In addition, age-related factors such as education, marital status, whether having children, status in the family, physical health, and personal income all have varying degrees of impact on suicide risks for rural youth. Conclusions: This study shows that there are some age-related risk factors for suicide at certain life stages and emphasizes that young adults in rural China aged 25 to 34 years have an increased risk of suicide as a result of experiencing more psychological strains with age.
\end{abstract}

Keywords: suicide; risk factors; adolescent; young adult 


\section{Introduction}

Suicide prevention is one of the World Health Organization's priorities in mental health for developing countries. According to data on suicide rates in 2002-2011 provided by the Chinese Ministry of Health $(\mathrm{MOH})$ and the National Population Census (NPC), the total number of suicide deaths was roughly 200,000 every year. The estimated mean national suicide mortality rate was 8.3 per 100,000 people each year in the most recent six years [1]. Even with a decrease of the suicide rates observed in China in the past decade [2,3], suicide has been identified as the number one cause of death in the country for those between 15 and 34 years of age [4]. Therefore, more empirical evidence is needed to advance our understanding of suicidal youth in the Chinese population to better understand how risk factors for suicide are related to different age groups. Only by recognizing those who are at risk for suicide and knowing how to provide treatment for suicidal individuals can improve how we deal with this urgent issue.

As Durkheim noted at the end of the nineteenth century, suicide rates increased with age. The lowest rates appeared among the young and the highest among the elderly [5]. However, this pattern has changed substantially in recent years. Researchers have documented that age trends in suicide rates for the United States follow a certain pattern that the incidence of suicide is sharp increased from youth (at their early twenties) to adulthood and, slightly decreased to a lower rate throughout middle age [6]. In recent years, suicide has become the third leading cause of death among persons aged 15 to 24 years, and the second among persons aged 25 to 34 years [7].

Youth suicide, as an especially significant aspect in the suicide literature, has drawn much attention in recent years [8-10]. Some studies focus on how mental health risk factors impact on youth suicidal behaviors [11]. It suggests that psychopathological symptoms are associated with suicidal behavior. Particularly, more than $90 \%$ of youth suicide victims have had at least one major psychiatric disorder, although younger adolescent ( $<16$ years) suicide victims have lower rates of psychopathology, averaging around $60 \%[12,13]$. Substance abuse is more common and leads to a much higher risk for suicide in the older ( $>$ or $=16$ years) vs. younger $(<16$ years) adolescents [12]. Depressive disorders (major depression, depressive disorders not otherwise specified, bipolar disorders, dysthymia) are consistently the most prevalent disorders among adolescent suicide victims, ranging from $49 \%$ to $64 \%$ of cases [14]. Other scholars pay more attention on the effect of sociodemographic factors [8], arguing the importance of childhood adversities, family characteristics, and socioeconomic status on studying suicide risks among young people [15-17]. For example, focusing on the importance of considering how social context impact age-related trajectories in suicide and homicide in high-income nations, Pampel and Williamson [18] demonstrate that increases in youth suicide rates are associated with increases in the size of the youngest (15-24 years of age) cohort, as well as recent changes in traditional family roles and family stability.

Unlike Western studies on suicidal youth, previous studies with Chinese data have documented some unique characteristics of Chinese rural young suicide victims. For example, scholars have argued that the suicide rate in women is higher than in men [19,20]; marriage does not play a protective role for suicide in rural China [21] and neither does religion [22]. In addition, other correlates, for example, multiple psychosocial factors and life stress are reported to be the risk factors for suicidal behaviors [23]. However, study on the suicide risk with age group comparisons is rare in China. 
This study is designed to test how suicide risks are different between adolescents aged 15 to 24 years and young adults aged 25 to 34 years in rural China. Several factors associated with individual age may potentially have influences on the correlation observed between age and suicide risk according to the previous studies [12]. In particular, those factors that included in the current study are education, marital status, whether having children, status in the family, physical health, and personal income.

In the suicide literature, several theories are commonly used to explain the mechanisms behind the suicidal behaviors among different social groups. One of the pioneers of sociology, Durkheim [5] showed in his classic study of suicide that it was more prevalent among individuals who were not married or who had no involvement in the church or community. His explanation was that individuals who were not well integrated into society had little social support, and, therefore, were at increased risk of suicide. To move beyond the traditional approach of using social integration as the dominant structural consideration to study suicide, a growing body of recent studies has used the strain theory of suicide to guide research [24,25]. According to the strain theory of suicide, suicide as well as mental disorders, can be preceded by psychological strains in the social structure [25]. A psychological strain is formed by at least two stressors [26,27], conflicting in an individual's life and leading to different directions, so that the individual will feel helpless, hopeless, and in a psychologically torturous situation [28]. For the strain theory of suicide, any of the four types of strains will increase individuals' suicide risk, and those strains result from differential values, discrepancy between aspiration and reality, relative deprivation, and lack of coping skills in a crisis. The connection between suicide and psychological strains in the form of all four sources has been tested and supported with a sample of suicide notes in the United States [28] and through psychological autopsy studies in rural China [25]. In the current study, we use Chinese rural youth suicide data to illustrate how age and age-related factors impact suicidal behavior. We also try to use strain theory of suicide to better understand these differences between adolescents and young adults in order to provide effective suicide prevention strategies and treatment programs for certain at-risk population.

\section{Methods}

\subsection{Subjects and Data Collection}

Data for the study were obtained from sixteen rural counties in three Chinese provinces (Liaoning, Hunan, and Shandong). It was a large psychological autopsy project investigating correlates of completed suicide in comparison with a group of living controls. In each of the 16 counties, suicides aged 15-34 years were sampled consecutively from October 2005 to June 2008. Similar numbers of community-living controls were recruited in the same counties for the same time periods. In this study, we have excluded cases of accidental or natural death in which suicidal intent was questioned. As China does not have a medical examiner system and all deaths are required to be sent to a health agency for a death certificate, hospitals are the primary place for the Centers for Disease Control and Prevention (CDC) to locate cases for the study. Each hospital uses a standard protocol to determine the cause of death. In remote rural areas far away from a hospital, village doctors are responsible for furnishing death certificates and are required to report the death to the Xiang (township) health agency. All the hospitals and clinics in the county are supervised by the county CDC. For our study, all suicidal 
deaths were required to be reported to each county $\mathrm{CDC}$ by telephone or fax on a daily basis, and the information gathered at the county CDC was then forwarded on a monthly basis to the provincial CDC. For those suicidal deaths that were not recognized by any health agency, our mortality registry system allowed the village treasurers, who collect fees for each burial or cremation and are aware of all the deaths in the village, to notify the Xiang health agency or the county CDC. Whenever necessary, an investigation with the village board and villagers was conducted by the research team to try to ensure that no suicide cases were missed, or reported erroneously. These procedures were implemented to minimize false classifications.

The community-living controls were from the same counties and from among the living general population within the same age group of the suicides. In each province, we used the 2005 census database of the counties in our research. For each suicide, we used the database of the county where the deceased lived to randomly select a living control in the same age range (i.e., 15-34 years). With regard to gender, the random selection of controls aged 15-34 years from each county database yielded approximately equal numbers of males and females, which approximated to the gender distribution of suicide cases in the study. The control sample did not exclude individuals who had been diagnosed with mental disorders or previous suicide attempts. Thus, the prevalence of mental disorders and suicidal attempts could be assessed in the rural general population aged 15-34, and more importantly, the effects (direct, moderating and intervening) of mental disorders on completed suicide could also be studied.

Face-to-face interviews were conducted in households in villages. In each selected county, suicide cases and living controls were enrolled and two informants (one family member and one friend or neighbor) were interviewed for each suicide case or control. The controls themselves were also interviewed with the same protocol to obtained further information of the study. As a result, 392 suicide cases and 416 community living controls were recruited in this study. The study protocol was approved by the Institutional Review Board at the State University of New York College at Buffalo, as well as by the three universities in China where the data collection was conducted. For the specific procedures in sampling and interviewing and our protocol for the human subjects protection, please refer to our previous publications [21,29]. Table 1 presents the demographic characteristics of the sample, as well as the major independent and dependent variables for the study with age groups comparisons.

\subsection{Measures}

The dependent variable is a dichotomous variable in which 0 represents a higher risk of death and 1 represents a lower risk of death. As mentioned above, suicide is a major social and public health problem in China. Thus, not only individual factors, but also a range of social factors are considered in attempts to explain suicidal behavior. Those predicting variables include gender, marital status, education, status in the family, whether having children, physical health, personal income and depression. Age ranged from 15 to 34 years, which was divided into two groups for further comparison. The two groups are adolescents aged 15 to 24 years and young adults aged 25 to 34 years. 
Table 1. Descriptions of the sample for the major variables and their age group comparisons.

\begin{tabular}{|c|c|c|c|c|c|c|c|c|c|c|c|c|c|c|c|c|c|c|}
\hline \multirow{3}{*}{ Variable } & \multicolumn{6}{|c|}{ All Subjects $(\mathrm{N}=\mathbf{8 0 8})$} & \multicolumn{6}{|c|}{ Suicide Cases $(\mathrm{N}=392)$} & \multicolumn{6}{|c|}{ Controls $(N=416)$} \\
\hline & \multicolumn{2}{|c|}{ Adolescents } & \multicolumn{2}{|c|}{ Young Adults } & \multicolumn{2}{|c|}{$\begin{array}{c}\text { Comparison } \\
\text { Statistes }^{\#} \\
\end{array}$} & \multicolumn{2}{|c|}{ Adolescents } & \multicolumn{2}{|c|}{ Young Adults } & \multicolumn{2}{|c|}{$\begin{array}{c}\text { Comparison } \\
\text { Statistes }^{\#} \\
\end{array}$} & \multicolumn{2}{|c|}{ Adolescents } & \multicolumn{2}{|c|}{ Young Adults } & \multicolumn{2}{|c|}{$\begin{array}{c}\text { Comparison } \\
\text { Statistes }^{\#} \\
\end{array}$} \\
\hline & $\begin{array}{c}\text { Mean } \\
\text { or f }\end{array}$ & $\begin{array}{c}\text { SD } \\
\text { or } \% \\
\end{array}$ & $\begin{array}{c}\text { Mean } \\
\text { or } \mathbf{f} \\
\end{array}$ & $\begin{array}{c}\text { SD } \\
\text { or } \% \\
\end{array}$ & $t / \chi^{2}$ & $p$ & $\begin{array}{c}\text { Mean } \\
\text { or } \mathbf{f} \\
\end{array}$ & $\begin{array}{c}\text { SD } \\
\text { or } \% \\
\end{array}$ & $\begin{array}{c}\text { Mean } \\
\text { or f }\end{array}$ & $\begin{array}{c}\text { SD } \\
\text { or } \% \\
\end{array}$ & $t / \chi^{2}$ & $p$ & $\begin{array}{c}\text { Mean } \\
\text { or } \mathbf{f}\end{array}$ & $\begin{array}{c}\text { SD } \\
\text { or } \% \\
\end{array}$ & $\begin{array}{c}\text { Mean } \\
\text { or f }\end{array}$ & $\begin{array}{c}\text { SD } \\
\text { or } \% \\
\end{array}$ & $t / \chi^{2}$ & $p$ \\
\hline Gender & & & & & 0.304 & 0.617 & & & & & 0.042 & 0.916 & & & & & 1.201 & 0.273 \\
\hline Women & 149 & $47.30 \%$ & 243 & $49.30 \%$ & & & 65 & $46.10 \%$ & 113 & $45.00 \%$ & & & 84 & $48.30 \%$ & 130 & $53.70 \%$ & & \\
\hline Men & 166 & $52.70 \%$ & 250 & $50.70 \%$ & & & 76 & $53.90 \%$ & 138 & $55.00 \%$ & & & 90 & $51.70 \%$ & 112 & $46.30 \%$ & & \\
\hline $\begin{array}{l}\text { Marital } \\
\text { status }\end{array}$ & & & & & 298.82 & $<0.001$ & & & & & 111.522 & $<0.001$ & & & & & 202.695 & $<0.001$ \\
\hline $\begin{array}{l}\text { Not } \\
\text { currently } \\
\text { married }\end{array}$ & 243 & $77.40 \%$ & 75 & $15.80 \%$ & & & 114 & $80.90 \%$ & 59 & $24.90 \%$ & & & 129 & $74.60 \%$ & 16 & $6.70 \%$ & & \\
\hline $\begin{array}{l}\text { Currently } \\
\text { married }\end{array}$ & 71 & $22.60 \%$ & 401 & $84.20 \%$ & & & 27 & $19.10 \%$ & 178 & $75.10 \%$ & & & 44 & $25.40 \%$ & 223 & $93.30 \%$ & & \\
\hline Education & 8.45 & 2.535 & 8.19 & 2.845 & 1.299 & 0.194 & 7.57 & 2.859 & 7.28 & 2.715 & 0.97 & 0.333 & 9.16 & 1.976 & 9.13 & 2.668 & 0.115 & 0.908 \\
\hline $\begin{array}{l}\text { Status in } \\
\text { the family }\end{array}$ & & & & & 10.117 & 0.006 & & & & & 8.053 & 0.018 & & & & & 14.216 & 0.001 \\
\hline Low & 21 & $6.70 \%$ & 42 & $8.60 \%$ & & & 14 & $9.90 \%$ & 42 & $16.80 \%$ & & & 7 & $4.00 \%$ & 0 & $0.00 \%$ & & \\
\hline Average & 284 & $90.20 \%$ & 408 & $83.10 \%$ & & & 121 & $85.80 \%$ & 184 & $73.60 \%$ & & & 163 & $93.70 \%$ & 224 & $92.90 \%$ & & \\
\hline High & 10 & $3.20 \%$ & 41 & $8.40 \%$ & & & 6 & $4.30 \%$ & 24 & $9.60 \%$ & & & 4 & $2.30 \%$ & 17 & $7.10 \%$ & & \\
\hline $\begin{array}{l}\text { Having } \\
\text { Children }\end{array}$ & & & & & 353.418 & $<0.001$ & & & & & 145.553 & $<0.001$ & & & & & 217.683 & $<0.001$ \\
\hline No & 272 & $86.30 \%$ & 93 & $18.90 \%$ & & & 126 & $89.40 \%$ & 65 & $25.90 \%$ & & & 146 & $83.90 \%$ & 28 & $11.60 \%$ & & \\
\hline Yes & 43 & $13.70 \%$ & 400 & $81.10 \%$ & & & 15 & $10.60 \%$ & 186 & $74.10 \%$ & & & 28 & $16.10 \%$ & 214 & $88.40 \%$ & & \\
\hline
\end{tabular}


Table 1. Cont.

\begin{tabular}{|c|c|c|c|c|c|c|c|c|c|c|c|c|c|c|c|c|c|c|}
\hline \multirow{3}{*}{ Variable } & \multicolumn{6}{|c|}{ All Subjects $(\mathrm{N}=\mathbf{8 0 8})$} & \multicolumn{6}{|c|}{ Suicide Cases $(\mathrm{N}=392)$} & \multicolumn{6}{|c|}{ Controls $(N=416)$} \\
\hline & \multicolumn{2}{|c|}{ Adolescents } & \multicolumn{2}{|c|}{ Young Adults } & \multicolumn{2}{|c|}{$\begin{array}{c}\text { Comparison } \\
\text { Statistes }^{\#} \\
\end{array}$} & \multicolumn{2}{|c|}{ Adolescents } & \multicolumn{2}{|c|}{ Young Adults } & \multicolumn{2}{|c|}{$\begin{array}{c}\text { Comparison } \\
\text { Statistes }^{\#} \\
\end{array}$} & \multicolumn{2}{|c|}{ Adolescents } & \multicolumn{2}{|c|}{ Young Adults } & \multicolumn{2}{|c|}{$\begin{array}{c}\text { Comparison } \\
\text { Statistes }^{\#}\end{array}$} \\
\hline & $\begin{array}{c}\text { Mean } \\
\text { or f }\end{array}$ & $\begin{array}{c}\text { SD } \\
\text { or } \%\end{array}$ & $\begin{array}{c}\text { Mean } \\
\text { or } f\end{array}$ & $\begin{array}{c}\text { SD } \\
\text { or \% }\end{array}$ & $t / \chi^{2}$ & $p$ & $\begin{array}{c}\text { Mean } \\
\text { or f }\end{array}$ & $\begin{array}{c}\text { SD } \\
\text { or } \%\end{array}$ & $\begin{array}{c}\text { Mean } \\
\text { or f }\end{array}$ & $\begin{array}{c}\text { SD } \\
\text { or \% }\end{array}$ & $t / \chi^{2}$ & $p$ & $\begin{array}{c}\text { Mean } \\
\text { or f }\end{array}$ & $\begin{array}{c}\text { SD } \\
\text { or \% }\end{array}$ & $\begin{array}{c}\text { Mean } \\
\text { or } \mathbf{f}\end{array}$ & $\begin{array}{c}\text { SD } \\
\text { or \% }\end{array}$ & $t / \chi^{2}$ & $p$ \\
\hline $\begin{array}{l}\text { Physical } \\
\text { Health }\end{array}$ & & & & & 25.608 & $<0.001$ & & & & & 25.626 & $<0.001$ & & & & & 2.134 & 0.344 \\
\hline Poor & 24 & $7.60 \%$ & 83 & $16.80 \%$ & & & 18 & $12.80 \%$ & 70 & $27.90 \%$ & & & 6 & $3.40 \%$ & 13 & $5.40 \%$ & & \\
\hline OK & 47 & $14.90 \%$ & 110 & $22.30 \%$ & & & 18 & $12.80 \%$ & 60 & $23.90 \%$ & & & 29 & $16.70 \%$ & 50 & $20.70 \%$ & & \\
\hline Good & 244 & $77.50 \%$ & 300 & $60.90 \%$ & & & 105 & $74.50 \%$ & 121 & $48.20 \%$ & & & 139 & $79.90 \%$ & 179 & $74.00 \%$ & & \\
\hline $\begin{array}{l}\text { Personal } \\
\text { income }\end{array}$ & & & & & 25.757 & $<0.001$ & & & & & 1.507 & 0.471 & & & & & 35.059 & $<0.001$ \\
\hline $\begin{array}{l}\text { Low } \\
(\leq 10,000)\end{array}$ & 214 & $70.60 \%$ & 252 & $55.10 \%$ & & & 97 & $70.30 \%$ & 156 & $64.50 \%$ & & & 117 & $70.90 \%$ & 96 & $44.70 \%$ & & \\
\hline $\begin{array}{l}\text { Average } \\
(10,001- \\
19,999) \\
\end{array}$ & 65 & $21.50 \%$ & 113 & $24.70 \%$ & & & 31 & $22.50 \%$ & 62 & $25.60 \%$ & & & 34 & $20.60 \%$ & 51 & $23.70 \%$ & & \\
\hline $\begin{array}{l}\operatorname{High}(\geq 20,0 \\
00)\end{array}$ & 24 & $7.90 \%$ & 92 & $20.10 \%$ & & & 10 & $7.20 \%$ & 24 & $9.90 \%$ & & & 14 & $8.50 \%$ & 68 & $31.60 \%$ & & \\
\hline $\begin{array}{l}\text { HAM-D } \\
\text { depression }\end{array}$ & 4.63 & 8.522 & 8.2 & 13.128 & -4.617 & $<0.001$ & 10.03 & 10.458 & 16.39 & 14.82 & -4.434 & $<0.001$ & 0.29 & 1.056 & 0.42 & 1.84 & -0.886 & 0.376 \\
\hline
\end{tabular}

\# All the significant differences are functions of the age. 
The Hamilton Depression Rating Scale (HAM-D Scale) was designed to evaluate the degree of and variance in depression [30]. It quickly became the standard measure of depression severity for clinical trials of antidepressants [31]. The Hamilton depression scale has been the gold standard for the assessment of depression for 40 years and is now the most commonly used measure of depression [32]. For each of the 24 items in the full version of the scale, respondents were asked to rate the severity of their depression by probing mood, feelings of guilt, suicide ideation, insomnia, agitation or retardation, anxiety, weight loss, and somatic symptoms. The translation of the 24-item scale was borrowed from Tang [33], and has already been tested with Chinese depressive inpatients showing good reliability and validity. There were two proxy interviews for each suicide case and each living control. The vast majority of the responses for the target person were the same or fairly similar. For different responses pertaining to the target person, we selected the response representing a positive symptom, because the other informant may not have had an opportunity to observe the specific characteristic or behavior. The range of potential HAM-D scores is from 0 to 76. A higher score indicates more severe depression. In addition to considering HAM-D depression score, we examined a self-reported measure of physical health, which was categorized as "poor," "OK," or "good."

To investigate the effect of marriage and marital experience on suicide risks between adolescents and young adults in rural China, we computed a variable with two categories. The group of "not currently married" included those young people who had never been married, were divorced, were separated, or were widowed. The group of "currently married" covered those who were currently married or involved in cohabitation.

For the question of "whether having children," the respondents were asked to mark "yes" with all positive responses and "no" with all negative responses. Based on the scale, the status in the family was categorized as "low," "average," or "high." Personal annual income was measured in Chinese Renminbi (RMB), which were divided into three levels based on the scale mean: low $(\leq 10,000)$, average (10,000-19,999), or high ( $\geq 20,000)$. One U.S. dollar was equivalent to about $7.50 \mathrm{RMB}$ at that time.

\subsection{Data Analysis and Certification of the Methods}

SPSS 21.0 was used for all statistical analysis. Coefficients have been converted to odds ratios (ORs) for the interpretation and 95\% confidence intervals would also be reported. Both authors of this study certify that we are responsible for the methods used in the data collection and data analyses.

\section{Results}

Table 1 illustrates the distribution (mean or frequency) of each of the expected correlates of suicide risk for all subjects and their comparison between adolescents (aged 15 to 24) and young adults (aged 25 to 34). In this study, adolescents $(\mathrm{N}=315)$ and young adults $(\mathrm{N}=493)$ accounted for about $39 \%$ and $61 \%$ of the sample, respectively. The distribution of the respondents according to gender shows a generally similar pattern for adolescents and young adults. A total of $47.3 \%$ of women and $52.7 \%$ of men are aged 15 to 24 years for the adolescents group, while $49.3 \%$ of women and $50.7 \%$ of men are aged 25 to 34 years for the young adults group.

Duration of education ranged from 0 to 15 years for the respondents in the adolescents group and from 0 to 18 years for the respondents in the young adults group. The means of education level for the 
adolescents group and the young adults group were thus 8.45 years and 8.19 years. Compared to the respondents in the adolescents group, those in the young adults group are more likely to be currently married $(84.2 \%)$ and have at least one child (81.1\%). They also consider themselves in either lower $(8.6 \%)$ or higher $(8.4 \%)$ status in the family compared to adolescents, although most of young adults $(83.1 \%)$ still report average in the scale. In addition, more respondents from young adults group report poorer physical health and higher personal annual income than the respondents from the adolescents group. As predicted in the literature, young adults aged 25 to 34 years are more likely to associate with higher score of depression as well (See Table 1).

T-test and Chi-square tests have been used for the comparison between the adolescents group and the young adults group on suicide risk and major variables. The results indicate that the respondents in young adults group have significant differences with those in adolescents group on marital status, status in the family, whether have children, physical health, personal income and depression level.

Bivariate analyses for adolescents (see Table 2) indicate that lower suicide risk has associated with higher education and lower depression level. The associations are statistically significant. Women tend to have higher suicide risk than men, but the data does not show any significant difference. For young adults aged 25 to 34 years (see Table 3), lower suicide risk is correlated with higher education, higher status in the family, better physical health, higher personal income, and lower depression score, all of which are statistically significant. Being married and having kids are also positively related to lower suicide risk in our sample.

Table 2. Bivariate Inter-correlations among Predictors and Suicide for Adolescents, 15-24 years of age $(\mathrm{N}=315)^{\#}$.

\begin{tabular}{|c|c|c|c|c|c|c|c|c|c|}
\hline Variable & $\begin{array}{c}\text { Case Control } \\
\text { Status } \\
\end{array}$ & Gender & $\begin{array}{c}\text { Marital } \\
\text { Status } \\
\end{array}$ & Education & $\begin{array}{c}\text { Status in } \\
\text { the Family }\end{array}$ & Children & $\begin{array}{c}\text { Physical } \\
\text { Health }\end{array}$ & $\begin{array}{c}\text { Personal } \\
\text { Income }\end{array}$ & $\begin{array}{c}\text { HAM } \\
\text {-D } \\
\end{array}$ \\
\hline Gender & -0.044 & - & & & & & & & \\
\hline $\begin{array}{l}\text { Marital } \\
\text { Status }\end{array}$ & 0.18 & $-0.528 * *$ & - & & & & & & \\
\hline Education & $0.418 * *$ & -0.068 & -0.091 & - & & & & & \\
\hline $\begin{array}{l}\text { Status in } \\
\text { the Family }\end{array}$ & 0.204 & -0.149 & 0.259 & 0.103 & - & & & & \\
\hline $\begin{array}{l}\text { Having } \\
\text { Children }\end{array}$ & 0.234 & $-0.588 * *$ & $0.988 * *$ & -0.082 & 0.398 & - & & & \\
\hline $\begin{array}{l}\text { Physical } \\
\text { Health }\end{array}$ & 0.187 & 0.089 & 0.203 & 0.070 & -0.305 & -0.016 & - & & \\
\hline $\begin{array}{l}\text { Personal } \\
\text { Income }\end{array}$ & -0.005 & $0.237 *$ & 0.271 & -0.047 & -0.011 & 0.031 & $0.304 * *$ & - & \\
\hline $\begin{array}{l}\text { HAM-D } \\
\text { Depression }\end{array}$ & $-0.739 * *$ & 0.073 & -0.090 & $-0.270 * *$ & $-0.103 *$ & -0.192 & $-0.172 * *$ & 0.023 & - \\
\hline
\end{tabular}

\footnotetext{
\# Gamma is used as measure of association; ** Correlation is significant at the 0.01 level (2-tailed);
}

* Correlation is significant at the 0.05 level (2-tailed). 
Table 3. Bivariate Inter-correlations among Predictors and Suicide for Young Adults, 25-34 years of age $(\mathrm{N}=493)$.

\begin{tabular}{|c|c|c|c|c|c|c|c|c|c|}
\hline Variable & $\begin{array}{c}\text { Case Control } \\
\text { Status } \\
\end{array}$ & Gender & $\begin{array}{c}\text { Marital } \\
\text { Status }\end{array}$ & Education & $\begin{array}{c}\text { Status in } \\
\text { the Family }\end{array}$ & Children & $\begin{array}{c}\text { Physical } \\
\text { Health }\end{array}$ & $\begin{array}{c}\text { Personal } \\
\text { Income }\end{array}$ & $\begin{array}{c}\text { HAM } \\
\text {-D }\end{array}$ \\
\hline Gender & -0.173 & - & & & & & & & \\
\hline $\begin{array}{l}\text { Marital } \\
\text { Status }\end{array}$ & $0.644 * *$ & $-0.763 * *$ & - & & & & & & \\
\hline Education & $0.462 * *$ & 0.026 & 0.073 & - & & & & & \\
\hline $\begin{array}{l}\text { Status in the } \\
\text { Family }\end{array}$ & $0.423 * *$ & -0.114 & $0.582 * *$ & 0.151 & - & & & & \\
\hline $\begin{array}{l}\text { Having } \\
\text { Children }\end{array}$ & $0.455 * *$ & $-0.706 * *$ & $0.971 * *$ & -0.007 & $0.367 *$ & - & & & \\
\hline $\begin{array}{l}\text { Physical } \\
\text { Health }\end{array}$ & $0.522 * *$ & -0.107 & $0.310 * *$ & 0.103 & 0.109 & 0.013 & - & & \\
\hline $\begin{array}{l}\text { Personal } \\
\text { Income }\end{array}$ & $0.412 * *$ & $0.377 * *$ & 0.127 & $0.376 * *$ & $0.202 *$ & -0.005 & $0.266 * *$ & - & \\
\hline $\begin{array}{l}\text { HAM-D } \\
\text { Depression }\end{array}$ & $-0.788 * *$ & $0.127 * *$ & $-0.435 * *$ & $-0.318 * *$ & $-0.337 * *$ & $-0.161 * *$ & $-0.469 * *$ & $-0.314 * *$ & - \\
\hline
\end{tabular}

\# Gamma is used as measure of association; ** Correlation is significant at the 0.01 level (2-tailed);

* Correlation is significant at the 0.05 level (2-tailed).

Unconditional logistic regression model is used for analyzing the data of the suicide subjects to illustrate how suicide risks are different between adolescents and young adults with the relevant variables controlled for. Hosmer-Lemeshow goodness-of-fit (GOF) tests help us decide whether the model is correctly specified (see Table 4). The p-value for model 1 is below 0.05 significant level (0.033) as a result of including the variable of depression, which indicates that we have to reject the model. Model 2 (without depression) shows that, controlling for other variables, the odd ratio of adolescents not experiencing suicide risk is 2.511 times higher than the odds for young adults, which indicates that young adults are more likely to experience higher risk for suicide in our sample. For all subjects, each additional year of education is consistently associated with a lower risk for suicide. The odd ratio associated with a one year increase in education is 1.309 (95\% CI 1.216 to 1.408), indicating the higher education, the lower the chance to experience suicide risk. The odd ratio of low family status respondents (0.196) indicates that individuals who feel like at low family status are more likely to have higher suicide risk and it is statistically significant at the $\alpha=0.05$ level. Compared to those who report good physical health, respondents who have poor or average health are more likely to have higher suicide risk. Compare to those respondents who have children in the family, the respondents who do not have children in the family are more likely to have higher suicide risk (OR $=0.367)$. In addition, individuals who have poor or average personal income show higher risk for suicide compared to those who report themselves as having a good personal income. With other variables controlled for, gender and marital status are not significant predictors in the logistic regression analyses. 
Table 4. Logistic multiple regression predicting suicide $(0=$ suicide; $1=$ control $)$ with major covariates for all subjects $(\mathrm{N}=808)$.

\begin{tabular}{|c|c|c|c|c|c|c|c|c|}
\hline \multirow{3}{*}{$\begin{array}{l}\text { Predictor } \\
\text { Education }\end{array}$} & \multicolumn{4}{|c|}{ Model 1} & \multicolumn{4}{|c|}{ Model 2} \\
\hline & \multirow{2}{*}{$\begin{array}{c}\text { OR } \\
1.265\end{array}$} & \multicolumn{2}{|c|}{$\begin{array}{c}95 \% \text { CI } \\
\text { (Lower-Upper) }\end{array}$} & \multirow{2}{*}{$\begin{array}{c}\boldsymbol{p} \\
<0.001\end{array}$} & \multirow{2}{*}{$\begin{array}{c}\text { OR } \\
1.309\end{array}$} & \multicolumn{2}{|c|}{$\begin{array}{c}95 \% \text { CI } \\
\text { (Lower-Upper) }\end{array}$} & \multirow{2}{*}{$\begin{array}{c}\boldsymbol{p} \\
<0.001\end{array}$} \\
\hline & & 1.137 & 1.407 & & & 1.216 & 1.408 & \\
\hline \multicolumn{9}{|l|}{ Age group } \\
\hline Adolescents & 1.708 & 0.808 & 3.608 & 0.161 & 2.511 & 1.479 & 4.263 & 0.001 \\
\hline Young adults & $1.0(-)$ & $1.0(-)$ & $1.0(-)$ & & $1.0(-)$ & $1.0(-)$ & $1.0(-)$ & \\
\hline \multicolumn{9}{|l|}{ Gender } \\
\hline Women & 0.692 & 0.416 & 1.152 & 0.157 & 1.011 & 0.711 & 1.438 & 0.950 \\
\hline Men & $1.0(-)$ & $1.0(-)$ & $1.0(-)$ & & $1.0(-)$ & $1.0(-)$ & $1.0(-)$ & \\
\hline \multicolumn{9}{|l|}{ Marital status } \\
\hline Not currently married & 0.763 & 0.308 & 1.893 & 0.560 & 0.772 & 0.417 & 1.43 & 0.411 \\
\hline Currently married & $1.0(-)$ & $1.0(-)$ & $1.0(-)$ & & $1.0(-)$ & $1.0(-)$ & $1.0(-)$ & \\
\hline \multicolumn{9}{|l|}{ Status in the family } \\
\hline Low & 0.621 & 0.138 & 2.801 & 0.535 & 0.196 & 0.065 & 0.594 & 0.004 \\
\hline Average & 2.448 & 0.967 & 6.197 & 0.059 & 1.615 & 0.823 & 3.17 & 0.163 \\
\hline High & $1.0(-)$ & $1.0(-)$ & $1.0(-)$ & & $1.0(-)$ & $1.0(-)$ & $1.0(-)$ & \\
\hline \multicolumn{9}{|l|}{ Having Children } \\
\hline No & 0.431 & 0.158 & 1.175 & 0.100 & 0.367 & 0.19 & 0.709 & 0.003 \\
\hline Yes & $1.0(-)$ & $1.0(-)$ & $1.0(-)$ & & $1.0(-)$ & $1.0(-)$ & $1.0(-)$ & \\
\hline \multicolumn{9}{|l|}{ Physical Health } \\
\hline Poor & 0.845 & 0.327 & 2.185 & 0.729 & 0.183 & 0.101 & 0.332 & $<0.001$ \\
\hline $\mathrm{OK}$ & 1.722 & 0.835 & 3.554 & 0.141 & 0.58 & 0.38 & 0.884 & 0.011 \\
\hline Good & $1.0(-)$ & $1.0(-)$ & $1.0(-)$ & & $1.0(-)$ & $1.0(-)$ & $1.0(-)$ & \\
\hline \multicolumn{9}{|l|}{ Personal income } \\
\hline Low $(\leq 10,000)$ & 0.567 & 0.259 & 1.243 & 0.157 & 0.556 & 0.33 & 0.939 & 0.028 \\
\hline $\begin{array}{l}\text { Average } \\
(10,001-19,999)\end{array}$ & 0.549 & 0.237 & 1.274 & 0.163 & 0.548 & 0.309 & 0.973 & 0.040 \\
\hline High $(\geq 20,000)$ & $1.0(-)$ & $1.0(-)$ & $1.0(-)$ & & $1.0(-)$ & $1.0(-)$ & $1.0(-)$ & \\
\hline HAM-D Depression & 0.527 & 0.464 & 0.599 & $<0.001$ & & & & \\
\hline Constant & 0.817 & & & 0.779 & 0.217 & & & 0.003 \\
\hline $\mathrm{R}^{2}$ & 0.719 & & & & 0.317 & & & \\
\hline Hosmer-Lemeshow $\left(\chi^{2}\right)$ & 16.737 & & & 0.033 & 11.778 & & & 0.161 \\
\hline
\end{tabular}

(-) Reference category.

Logistic regression analysis has also been used for age group comparison in the study (see Table 5). The model fit for the young adults group $\left(R^{2}=0.445\right)$ is better than for the adolescents group $\left(R^{2}=0.180\right)$. Education is a strong predictor for both age groups on suicide risk. Among adolescents, respondents who have poor physical health $(\mathrm{OR}=0.845)$ are more likely to have higher suicide risk compare to those who report good physical health. However, we do not find a significant difference on suicide risk between respondents who report average physical health and good health.

In the young adult group, respondents who report a poor physical health $(p<0.001)$ and an average physical health (0.001) are found to have higher suicide risk than those who report a good physical 
health. In addition, "whether have children" is another significant predictor in the young adults group, indicating that people who do not have children have a higher suicide risk. People who have lower personal income also shows higher risk for suicide compared to people who have high personal income among young adults. With other variables controlled for, gender, marital status, and status in the family are not significant predictors for either age group in the logistic regression analyses.

Table 5. Logistic multiple regression predicting suicide $(0=$ suicide; $1=$ control $)$ for age group comparisons.

\begin{tabular}{|c|c|c|c|c|c|c|c|c|}
\hline \multirow{3}{*}{$\begin{array}{l}\text { Predictor } \\
\text { Education }\end{array}$} & \multicolumn{4}{|c|}{ Adolescents $(\mathbf{N}=\mathbf{3 1 5})$} & \multicolumn{4}{|c|}{ Young adults $(\mathrm{N}=493)$} \\
\hline & \multirow{2}{*}{$\begin{array}{c}\text { OR } \\
1.321 \\
\end{array}$} & \multicolumn{2}{|c|}{$\begin{array}{c}95 \% \text { CI } \\
\text { (lower-upper) }\end{array}$} & \multirow{2}{*}{$\begin{array}{c}\boldsymbol{p} \\
<0.001\end{array}$} & \multirow{2}{*}{$\begin{array}{c}\text { OR } \\
1.285 \\
\end{array}$} & \multicolumn{2}{|c|}{$\begin{array}{c}95 \% \text { CI } \\
\text { (lower-upper) }\end{array}$} & \multirow{2}{*}{$\begin{array}{c}\boldsymbol{p} \\
<0.001 \\
\end{array}$} \\
\hline & & 1.174 & 1.486 & & & 1.167 & 1.415 & \\
\hline \multicolumn{9}{|l|}{ Gender } \\
\hline Women & 0.922 & 0.556 & 1.529 & 0.753 & 1.073 & 0.646 & 1.782 & 0.786 \\
\hline Men & $1.0(-)$ & $1.0(-)$ & $1.0(-)$ & & $1.0(-)$ & $1.0(-)$ & $1.0(-)$ & \\
\hline \multicolumn{9}{|l|}{ Marital status } \\
\hline Not currently married & 0.898 & 0.396 & 2.035 & 0.796 & 0.470 & 0.171 & 1.293 & 0.144 \\
\hline Currently married & $1.0(-)$ & $1.0(-)$ & $1.0(-)$ & & $1.0(-)$ & $1.0(-)$ & $1.0(-)$ & \\
\hline \multicolumn{9}{|l|}{ Status in the family } \\
\hline Low & 0.755 & 0.127 & 4.476 & 0.757 & - & - & - & $0.997^{\#}$ \\
\hline Average & 2.313 & 0.537 & 9.964 & 0.260 & 1.723 & 0.779 & 3.810 & 0.179 \\
\hline High & $1.0(-)$ & $1.0(-)$ & $1.0(-)$ & & $1.0(-)$ & $1.0(-)$ & $1.0(-)$ & \\
\hline \multicolumn{9}{|l|}{ Having Children } \\
\hline No & 0.559 & 0.202 & 1.550 & 0.264 & 0.318 & 0.132 & 0.770 & 0.011 \\
\hline Yes & $1.0(-)$ & $1.0(-)$ & $1.0(-)$ & & $1.0(-)$ & $1.0(-)$ & $1.0(-)$ & \\
\hline \multicolumn{9}{|l|}{ Physical Health } \\
\hline Poor & 0.345 & 0.121 & 0.981 & 0.046 & 0.145 & 0.069 & 0.307 & $<0.001$ \\
\hline $\mathrm{OK}$ & 1.056 & .534 & 2.087 & 0.877 & 0.395 & 0.226 & 0.691 & 0.001 \\
\hline Good & $1.0(-)$ & $1.0(-)$ & $1.0(-)$ & & $1.0(-)$ & $1.0(-)$ & $1.0(-)$ & \\
\hline \multicolumn{9}{|l|}{ Personal income } \\
\hline $\operatorname{Low}(\leq 10,000)$ & 0.917 & 0.364 & 2.308 & 0.854 & 0.428 & 0.220 & 0.832 & 0.012 \\
\hline $\begin{array}{l}\text { Average } \\
(10,001-19,999)\end{array}$ & 0.800 & 0.290 & 2.206 & 0.666 & 0.518 & 0.250 & 1.071 & 0.076 \\
\hline High $(\geq 20,000)$ & $1.0(-)$ & $1.0(-)$ & $1.0(-)$ & & $1.0(-)$ & $1.0(-)$ & $1.0(-)$ & \\
\hline Constant & 0.122 & & & 0.042 & 0.341 & & & 0.090 \\
\hline $\mathrm{R}^{2}$ & 0.180 & & & & 0.445 & & & \\
\hline Hosmer-Lemeshow $\left(\chi^{2}\right)$ & 4.888 & & & 0.770 & 6.691 & & & 0.570 \\
\hline
\end{tabular}

\# The uncertainty of parameter estimation is due to the multicollinearity in the model; (-) Reference category.

\section{Discussion}

Previous studies have focused on different risk factors between suicide group and control group [34]. This study is organized around two main goals. First, it is to find out whether age differences exist among at-risk people in rural China so that we can pay more attention on reducing suicide risks for a particular age group. Second, it should be known if certain age-related factors such as education, 
marital status, whether have children, status in the family, physical health, and personal income play roles in either decreasing or increasing suicide risks for adolescents and young adults in rural China that can help us have a better understanding of Chinese rural youth suicide. Our findings indicate that there is a difference between two age groups concerning suicide risks and young adults have faced more suicide risk factors than adolescents in rural China.

We have found that women in the adolescents group have higher risk for suicide than men, whereas women in the young adults group have lower risk for suicide than men. However, the gender difference does not show significant impact in our sample. Another non-significant predictor is status in the family. Although low family status is likely to lead to high suicide risk for all subjects in our model, we don't find different effects between two age groups due to the multicollinearity as fewer cases in the young adults group. More studies are needed in the future.

According to the strain theory of suicide, the four sources of strain are: (a) differential value conflicts, (b) discrepancies between aspiration and reality, (c) relative deprivation, and (d) lack of coping skills. The differences between two age groups on suicide risks in rural China can be partially explained by the strain theory of suicide because young adults have potentially experienced more conflicting life stressors in their life than adolescents and, therefore, are more likely to produce psychological strains.

For example, our results show that education and physical health are significant predicators for suicide risk for both respondents in the adolescents group and young adults group. Education plays a key role in providing individuals with knowledge about coping skills. Individuals, including adolescents and young adults, who have higher education will have better coping skills to lower the risk for suicide in rural China. Compared to an adolescent, if an individual have entered into adulthood, both society and the individual will have certain expectations for his or her life, such as being employed or taking care of his or her family. However, if a young adult does not have a good physical health he or she may have to face the reality that he or she might fail to reach his or her aspirations. These discrepancies between his or her aspirations and reality may produce strains and, then, lead to increased risk for suicide.

Furthermore, for young adults aged 25 to 34 years, getting married and having kids are important transitions in their life stage for people in rural China. Researchers have studied the order in which life events and transitions occur and their effects on mental health. They suggest that the effects of stressful events may vary, depending on the event and the age of exposure [35,36]. In rural China, it is very rare for an individual who is older than 25 to be single or not have kids. It is a shame for the individual or even for the whole family so that values strains may occur because of these circumstances. Therefore, although the effect of marital status on suicide risk is not statistically significant between adolescents and young adults, individuals who are not currently married and do not have children among age 25 to 34 will feel more stress from both family and society, which may produce value strains and thus increase their risk for suicide.

In addition, low personal income shows a statistically significant impact on suicide risk among young adults. Stack [37] found that relative deprivation (i.e., income inequality), instead of a single life stressor (i.e., income crisis), would be better explanation for the risk of suicide. According to the strain theory of suicide, in the situation where a poor individual realizes that other people of the same or 
similar background are leading a much better life, the person may experience the deprivation strain. This might be a possible reason leading the increased risk for suicide.

In sum, the age-related factors are more observable in young adults aged 25 to 34 years than in adolescents aged 15 to 24 years in rural China. Such factors as education, physical health, whether have children and personal income should be paid more attention to in this particular population. Suicide behaviors have been identified as consequences of psychological strains, according to the theory. Therefore, we can develop suicide prevention strategies by eliminating the strains rather than removing life stress to reduce the risks of suicide. To some extent, encouraging higher education and providing job training can reduce the value strains, aspiration strain, and deprivation strain, as well as improve one's coping strategies. The current study is limited by its data collection approach and is, therefore, not able to study how these risk factors affect Chinese rural young subjects in their later life. Further studies are needed to move beyond looking simply at the existence of these risk factors and their relationship to suicide. Instead, we should pay attention to whether age-related life events appear within the sequence because it is important to consider in studying individuals' later mental health outcomes, including suicide.

\section{Conclusions}

Our study indicates that young adults have faced more suicide risk factors than adolescents in rural China. Strain theory of suicide contributes a new perspective for us to better understand this circumstance and provides some effective ways for rural young adults to lower suicide risks in the society.

\section{Acknowledgments}

This research was supported by a grant of U.S. NIMH: R01 MH068560, for which the second author is PI. The research also received support from the 211 Project Funds (09SH003) granted to the Central University of Finance and Economics by Chinese Ministry of Education.

\section{Author Contributions}

Sibo Zhao did the data analysis, wrote up the paper, and facilitated the final submission of the manuscript. Jie Zhang conceptualized the theoretical frame, designed the study, and provided critical and constructive comments to the manuscript.

\section{Conflicts of Interest}

The authors declare no conflict of interest.

\section{References}

1. Zhang, J.; Sun, L.; Liu, Y.; Zhang, J. The change in suicide rates between 2002 and 2011 in China. Suicide Life-Threaten. Behav. 2014, 44, 560-568.

2. Zhang, J.; Ma, J.; Jia, C.; Sun, J.; Guo, X.; Xu, A.; Li, W. Economic growth and suicide rate changes: A case in china from 1982 to 2005. Eur. Psychiat. 2010, 25, 159-163. 
3. Wang, C.-W.; Chan, C.W.; Yip, P.F. Suicide rates in china from 2002 to 2011: An update. Soc. Psychiat. Psychiat. Epidem. 2014, 49, 929-941.

4. Wang, S.; Li, Y.; Chi, G.; Xiao, S.; Ozanne-Smith, J.; Stevenson, M.; Phillips, M. Injury-related fatalities in china: An under-recognised public-health problem. Lancet 2008, 372, 1765-1773.

5. Durkheim, E. Suicide: A Study in Sociology; Free Press: Glencoe, IL, USA, 1951.

6. Stockard, J.; O'Brien, R.M. Cohort variations and changes in age-specific suicide rates over time: Explaining variations in youth suicide. Soc. Forces 2002, 81, 605-642.

7. Evans, E.; Hawton, K.; Rodham, K.; Deeks, J. The prevalence of suicidal phenomena in adolescents: A systematic review of population-based studies. Suicide Life-Threaten. Behav. 2005, 35, 239-250.

8. Maimon, D.; Kuhl, D.C. Social control and youth suicidality: Situating durkheim's ideas in a multilevel framework. Amer. Sociol. Rev. 2008, 73, 921-943.

9. Houston, K.; Hawton, K.; Shepperd, R. Suicide in young people aged 15-24: A psychological autopsy study. J. Affect. Disorders 2001, 63, 159-170.

10. Cerel, J.; Roberts, T.A. Suicidal behavior in the family and adolescent risk behavior. J. Adolescent Health 2005, 36, doi:10.1016/j.jadohealth.2004.08.010.

11. Verona, E.; Javdani, S. Dimensions of adolescent psychopathology and relationships to suicide risk indicators. J. Youth Adolescence 2011, 40, 958-971.

12. Brent, D.A.; Baugher, M.; Bridge, J.; Chen, T.; Chiappetta, L. Age- and sex-related risk factors for adolescent suicide. J. Amer. Acad. Child Adolesc. Psy. 1999, 38, 1497-1505.

13. Beautrais, A.L. Child and young adolescent suicide in New Zealand. Aust. N. Z. J. Psychiat. 2001, 35, 647-653.

14. Shaffer, D.; Gould, M.S.; Fisher, P.; Trautman, P.; Moreau, D.; Kleinman, M.; Flory, M. Psychiatric diagnosis in child and adolescent suicide. Arch. Gen. Psychiat. 1996, 53, 339-348.

15. Bruffaerts, R.; Demyttenaere, K.; Borges, G.; Haro, J.M.; Chiu, W.T.; Hwang, I.; Karam, E.G.; Kessler, R.C.; Sampson, N.; Alonso, J.; et al. Childhood adversities as risk factors for onset and persistence of suicidal behaviour. Brit. J. Psychiat. 2010, 197, 20-27.

16. Brooks-Gunn, J.; Duncan, G.J.; Aber, J.L. Neighborhood Poverty: Context and Consequences for Children; Russell Sage Foundation: New York, NY, USA, 1997; Volume 1.

17. Xing, X.-Y.; Tao, F.-B.; Wan, Y.-H.; Xing, C.; Qi, X.-Y.; Hao, J.-H.; Su, P.-Y.; Pan, H.-F.; Huang, L. Family factors associated with suicide attempts among chinese adolescent students: A national cross-sectional survey. J. Adolescent Health 2010, 46, 592-599.

18. Pampel, F.C.; Williamson, J.B. Age patterns of suicide and homicidemortality rates in high-income nations. Soc. Forces 2001, 80, 251-282.

19. He, Z.X.; Lester, D. The gender difference in Chinese suicide rates. Arch. Suicide Res. 1997, 3, 81-89.

20. Phillips, M.R.; Li, X.; Zhang, Y. Suicide rates in China, 1995-1999. Lancet 2002, 359, 835-840.

21. Zhang, J. Marriage and suicide among Chinese rural young women. Soc. Forces 2010, 89, 311-326.

22. Zhang, J.; Liu, E.Y. The confucian ethic of female subordination and depression among young people in rural China. Interdiscipl. J. Res. Relig. 2012, 8, 1-12.

23. Liu, X.; Tein, J.-Y.; Zhao, Z.; Sandler, I.N. Suicidality and correlates among rural adolescents of China. J. Adolescent Health 2005, 37, 443-451. 
24. Zhang, J.; Xiao, S.; Zhou, L. Mental disorders and suicide among young rural Chinese: A case-control psychological autopsy study. Amer. J. Psychiat. 2010, 167, 773-781.

25. Zhang, J.; Wieczorek, W.F.; Conwell, Y.; Tu, X.M. Psychological strains and youth suicide in rural China. Soc. Sci. Med. 2011, 72, 2003-2010.

26. Merton, R.K. Social Theory and Social Structure; Free Press: New York, NY, USA, 1957.

27. Agnew, R. Pressured into Crime: An Overview of General Strain Theory; Roxbury Publishing: Los Angeles, CA, USA, 2006.

28. Zhang, J.; Lester, D. Psychological tensions found in suicide notes: A test for the strain theory of suicide. Arch. Suicide Res. 2008, 12, 67-73.

29. Zhang, J.; Wieczorek, W.F.; Conwell, Y.; Tu, X.M.; Wu, B.Y.W.; Xiao, S.; Jia, C.X. Characteristics of young rural Chinese suicides: A psychological autopsy study. Psychol. Med. 2010, 40, 581-589.

30. Hamilton, M. A rating scale for depression. J. Neurol. Neurosurg. Psychiat. 1960, 23, 56-62.

31. Demyttenaere, K.; de Fruyt, J.; Rgen, U. Getting what you ask for: On the selectivity of depression rating scales. Psychother. Psychosom. 2003, 72, 61-70.

32. Williams, J.B. Standardizing the hamilton depression rating scale: Past, present, and future. Eur. Arch. Psychiat. Clin. Neuros. 2001, 251, 6-12.

33. Tang, Y.H. Hamilton depression scale. Shanghai Psychiat. Med. 1984, 2, 61-64. (in Chinese)

34. Zhang, J.; Li, N.; Tu, X.-M.; Xiao, S.; Jia, C. Risk factors for rural young suicide in China: A case-control study. J. Affect. Disorders 2011, 129, 244-251.

35. George, L.K. Sociological perspectives on life transitions. Annu. Rev. Sociol. 1993, 19, 353-373.

36. Kessler, R.C. The effects of stressful life events on depression. Annu. Rev. Psychol. 1997, 48, 191-214.

37. Stack, S. Suicide: A 15-year review of the sociological literature, part II: Modernization and social integration. Suicide Life-Threaten. Behav. 2000, 30, 163-176.

(C) 2014 by the authors; licensee MDPI, Basel, Switzerland. This article is an open access article distributed under the terms and conditions of the Creative Commons Attribution license (http://creativecommons.org/licenses/by/4.0/). 